\title{
Spring Update: A Letter from the President of the Korean Cleft Palate-Craniofacial Association
}

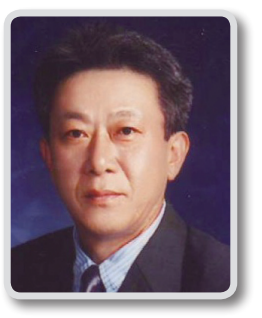

Youngman Lee

President of Korean Cleft Palate-Craniofacial Association
Dear Members of the Korean Cleft Palate-Craniofacial Association,

The Korean Cleft Palate-Craniofacial (KCPC) Association invites you to the annual symposium in Jeju Island on the month of April, with 'Mastery of Facial Bone Fracture' as the theme this year. Management of facial bone fractures is a basic but important practice for plastic and reconstructive surgeons. Through this symposium, we would like to have an in-depth discussion about the management of facial bone fractures.

Thanks to your continued interest and participation, the Association has been growing in membership year after year and continue to advance South Korean plastic surgery to a global playing field. One such ongoing effort is the "Korean Session" to be held at the 23rd Congress of European Association for Cranio-MaxilloFacial Surgery in United Kingdom this September. Members of
KCPC Association are encouraged to attend and participate in demonstrating the up-to-date practice of Korean craniofacial surgery to the rest of the world.

In the year 2016, my hope is that our Association resumes the influential role that craniofacial surgery played in beginning of plastic surgery and restores the confidence from our medical colleagues and our patients.

On behalf of the Association, I would like to express my sincere appreciation for those teachers who have contributed to the development of Korean craniofacial surgery. Likewise, I support the effort of young teachers who are leading us into a new future for Korean craniofacial surgery.

We thank you for the continued confidence and support in the Association.

\footnotetext{
Correspondence: Youngman Lee

Department of Plastic and Reconstructive Surgery, Soonchunhyang University Cheonan Hospital, 31 Suncheonhyang 6-gil, Dongnam-gu, Cheonan 31151, Korea E-mail: youngman@schmc.ac.kr

Received March 15, 2016 / Revised March 16, 2016 / Accepted March 16, 2016
} 